\title{
PROJECT SYSTEM, UN MODELO DE GESTIÓN PARA CONSTRUIR EL DESARROLLO SOSTENIBLE
}

\author{
Federico Dejo \\ Universidad ESAN \\ fdejo@esan.edu.pe \\ fadejo@gmail.com
}

\section{Resumen}

En el presente artículo se exponen las ventajas del método del Tablero de Mando Project System como herramienta computarizada y totalmente integrada que hace más sencillas, rápidas y eficaces las tareas de elaboración y seguimiento de los diagnósticos, los planes y los proyectos que forman parte de una visión estratégica para alcanzar el desarrollo sostenible. Se exponen las características y la utilidad de cada una de las herramientas y se establece la secuencia que les corresponde dentro del ciclo de retroalimentación en el proceso de gestión territorial, sea que se trate de comunidades campesinas, gobiernos locales, gobiernos regionales o empresas con planes de responsabilidad social.

Palabras clave: desarrollo sostenible, planificación, proyectos, diagnóstico integral, monitoreo, evaluación, marco lógico, matriz de sostenibilidad.

\begin{abstract}
This paper shows the advantages of the Scorecard Project System as a computer integrated tool to simplify, speed up and streamline the design and monitoring of diagnosis studies, plans and projects included in a strategic view to reach sustainable development. The paper shows the characteristics and advantages of each such tool and establishes their sequence in the feedback cycle for territorial management, whether peasant communities, local governments, regional governments of companies with a social responsibility mission.
\end{abstract}

Key words: sustainable development, planning, projects, comprehensive diagnosis, monitoring, evaluation, logframe, sustainability matrix. 


\section{Introducción}

La compleja realidad de los escenarios donde se ejecutan las inversiones en minerales e hidrocarburos se manifiesta en constantes conflictos entre el Estado, las empresas productoras, las autoridades y la población civil; lo que genera pérdidas que afectan el desarrollo de todos los agentes, en especial al restarles oportunidades a las poblaciones que sufren una mayor escasez de recursos y están en situación de pobreza.

A pesar de la gran cantidad de dinero que se invierte en proyectos en las diversas regiones provenientes de los fondos que aportan la minería, el gas y el petróleo, las poblaciones continúan reclamando por la falta de impactos positivos en su calidad de vida; por el contrario, son evidentes el temor y el recelo por la posible contaminación de los recursos naturales, la afectación de la salud de las personas y los animales, y la alteración del entorno natural.

En este contexto, los conflictos políticos e ideológicos encuentran un escenario favorable para desarrollarse, lo que hace cada vez más difícil la obtención de la licencia social de las comunidades para que las empresas puedan desarrollar sus actividades en un entorno de paz social y colaboración con los diversos agentes de desarrollo.

Una de las principales causas de la falta de efectividad e impacto de las inversiones sociales y productivas es la carencia de una adecuada calidad de gestión en el manejo de los escenarios complejos. Las inversiones se realizan más como una reacción ante los problemas o los pedidos urgentes de las comunidades y sin estar sustentadas en un diagnóstico objetivo y científico que permita partir de un plan con capacidad de manejar tanto las urgencias como la visión de mediano y largo plazo. Más aún, no se actúa sopesando y diferenciando lo que es fundamental de lo que es accesorio. Por tanto, no llama la atención que los problemas y los conflictos sociales sean recurrentes, a pesar de las importantes inversiones que se realizan pues, muchas veces, estas carecen de una finalidad adecuada y de una debida complementación que permita el desarrollo de sinergias.

El propósito del modelo de gestión que se expone a continuación es ayudar a que aquellas comunidades que se encuentran en una situación crítica o semicrítica, y por tanto experimentan frecuentes conflictos sociales, puedan avanzar a otra realidad donde los indicadores evidencien que ya se alcanzó el desarrollo sostenible y predominen el entendimiento y la paz social, situación óptima que es el objetivo principal de la metodología del Project System.

La aplicación de este modelo ayudará de manera importante a que las inversiones sociales y productivas en beneficio de las poblaciones con graves carencias se hagan sobre la base de un conocimiento más preciso de sus necesidades y prioridades, además de ofrecer un conjunto de herramientas que garanticen la formulación y la gestión de los planes y los proyectos con base en metas y resultados, con un eficiente manejo y monitoreo de los procesos.

La hoja de ruta de este modelo identifica tres etapas posibles de desarrollo en las comunidades en las cuales se considera intervenir mediante un Plan de Inversiones. Cada etapa se identifica con un fondo (trama negra, intermedia y clara) y expresa el estadio de desarrollo en el que se encuentra en función al objetivo principal que es llegar al desarrollo sostenible. Estas etapas son las siguientes: 


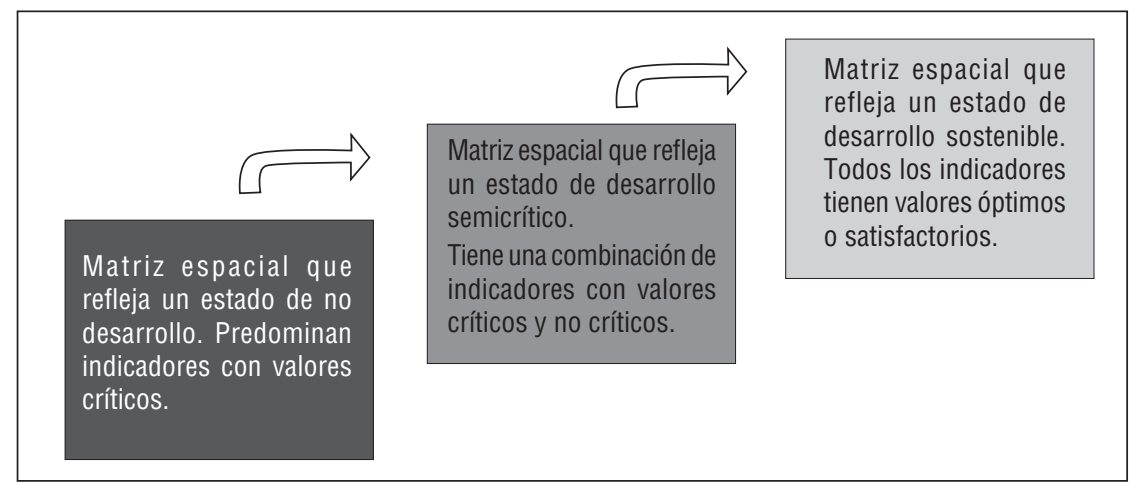

Gráfico 1

Secuencia de desarrollo espacial según metodología del Project System

La matriz clara es el estado objetivo al que las sociedades deben llegar. Pero ese nivel hoy en día es todavía privilegio de pocos países y mantenerse en él requiere tener niveles muy altos de eficiencia en los diferentes componentes del sistema territorial. A la vez, si no se llega a este, el deterioro del planeta será cada vez mayor. La solución no puede ser otra que desarrollar propuestas que nos permitan avanzar hasta el nivel superior. Y, para ello, las herramientas del Project System son una gran ayuda para evitar decisiones que pueden conducir a la repetición de errores.

\section{El Modelo de Sostenibilidad Territorial}

La propuesta que se desarrolla en este modelo de gestión se sustenta en la Metodología Sistémica de la Planificación y la Gestión Territorial; para ello utiliza la herramienta computarizada Project System. Esta herramienta se maneja desde un tablero de mando, el cual contiene todos los pasos metodológicos y los instrumentos necesarios para hacer una gestión territorial en función del desarrollo sostenible, facilitando la participación de todos los

\section{Cuadro 1. Tablero de mando del modelo de planificación y desarrollo sostenible del Project System}

\begin{tabular}{|c|c|c|c|c|c|c|}
\hline \multicolumn{7}{|c|}{ MENÚ DEL SISTEMA } \\
\hline INTRODUCCIÓN & \multicolumn{2}{|c|}{ DIAGNÓSTICO ESPACIAL } & \multicolumn{3}{|c|}{ PLANIFICACIÓN Y EJECUCIÓN } & \multirow{2}{*}{\begin{tabular}{|c|} 
MONITOREO \\
Monitoreo del \\
Plan Estratégico
\end{tabular}} \\
\hline $\begin{array}{l}\text { Presentación } \\
\text { del modelo }\end{array}$ & $\begin{array}{l}\text { Subsistemas } \\
\text { del espacio de } \\
\text { intervención }\end{array}$ & $\begin{array}{l}\text { Diagnóstico } \\
\text { sistémico }\end{array}$ & Plan estratégico & $\begin{array}{c}\text { Formulación } \\
\text { y gestión de } \\
\text { proyectos }\end{array}$ & $\begin{array}{c}\text { Plan Operativo } \\
\text { Anual }\end{array}$ & \\
\hline $\begin{array}{l}\text { Entender el } \\
\text { concepto del } \\
\text { modelo } \\
\text { Ir a la Guía } \\
\text { del Usuario }\end{array}$ & $\begin{array}{l}\text { 1. Identificar } \\
\text { sistema } \\
\text { espacial } \\
\text { 2. Definir } \\
\text { subsistemas y } \\
\text { variables } \\
\text { 3. Evaluar } \\
\text { variables }\end{array}$ & $\begin{array}{l}\text { 1. Ver la Matriz } \\
\text { de Sosteni- } \\
\text { bilidad } \\
\text { 2. Construir la } \\
\text { visión de } \\
\text { desarrollo }\end{array}$ & $\begin{array}{l}\text { Elaborar la } \\
\text { Matriz de } \\
\text { Planificación } \\
\text { Multianual }\end{array}$ & $\begin{array}{l}\text { - Guía de } \\
\text { Proyectos del } \\
\text { SNIP } \\
\text { - Marco lógico } \\
\text { - Guía para } \\
\text { planes de } \\
\text { negocios }\end{array}$ & $\begin{array}{l}\text { Elaborar la } \\
\text { matriz del Plan } \\
\text { Operativo Anual }\end{array}$ & $\begin{array}{l}\text { Elaborar el } \\
\text { avance del Plan } \\
\text { Estratégico }\end{array}$ \\
\hline
\end{tabular}

Fuente: (C) Federico A. Dejo. Derechos Reservados. 
sectores y los agentes de las comunidades del entorno de las áreas de inversión (ver cuadro 1).

La herramienta principal que sustenta el modelo es la Matriz de Sostenibilidad. Esta matriz delimita el espacio de influencia de las empresas inversoras y lo desagrega en subsistemas (recursos naturales, poblacionales, técnicos, económicos, científicos y productivos, institucionales, políticos, culturales y normativos, entre otros), con sus respectivas variables e indicadores, los que luego son evaluados en forma cuantitativa y cualitativa por la población o sus representantes y los técnicos especialistas en desarrollo. Se obtiene de esta manera una imagen que distingue por tramas (negra, mediana y clara) los diferentes estados en que se pueden encontrar las variables de los subsistemas del territorio estudiado. A partir de este instrumento, la definición de prioridades de inversión y su programación en un calendario de corto, mediano y largo plazo es más sencilla y confiable en cuanto a los resultados y los impactos esperados (ver cuadro 2).

Observando los resultados de esta matriz, se podrá notar, por ejemplo, que no tiene sentido invertir primero en la construcción de una costosa pileta que adorne un parque cuando hay graves problemas de analfabetismo o desnutrición infantil. Recién cuando se considere que estos últimos problemas están solucionados es que se puede decidir la inversión en la pileta, salvo que aún existan otros problemas graves que requieran atención prioritaria y, por tanto, la pileta tiene que seguir esperando en cuanto a la asignación de recursos para su construcción. Toda esta estrategia de inversiones con su programación se hace construyendo la Matriz de Planificación Multianual, herramienta que viene incluida en el Project System y permite el manejo simultáneo de todos los proyectos, en sus fases de formulación y ejecución.

\section{La delimitación de los subsistemas}

La puerta de entrada al método de gestión automatizada es la delimitación de los subsistemas y las variables que componen la estructura de cada uno de ellos. Se solicita para ello una imagen que permita apreciar la naturaleza del sistema global. En seguida se desagrega este en los correspondientes subsistemas que se interrelacionan entre sí dándole funcionamiento, dinamismo $\mathrm{y}$ sostenibilidad (ver cuadro 3).

Cuando el programa ha registrado los subsistemas por los nombres asignados, se autogenera un subtablero con un menú mediante el cual se podrá pasar a la siguiente fase, es decir, la de identificar las variables para cada subsistema y luego proceder a la tarea de operacionalizar cada una de ellas.

La evaluación de los subsistemas y las variables que componen el espacio territorial se hace construyendo indicadores que permiten medir el estado en el cual se encuentran al momento del diagnóstico territorial. A su vez, ese momento puede ser la Línea de Base del Plan de Desarrollo Sostenible, de manera que, año a año, de repetirse la medición, se podrá saber si realmente se están produciendo los cambios esperados en beneficio del medio ambiente y la población y, de ser necesario, hacer las correcciones pertinentes para poder llegar a los objetivos deseados (ver cuadro 4).

En la matriz se puede observar que hay una secuencia de izquierda a derecha que busca concretar el significado de la 


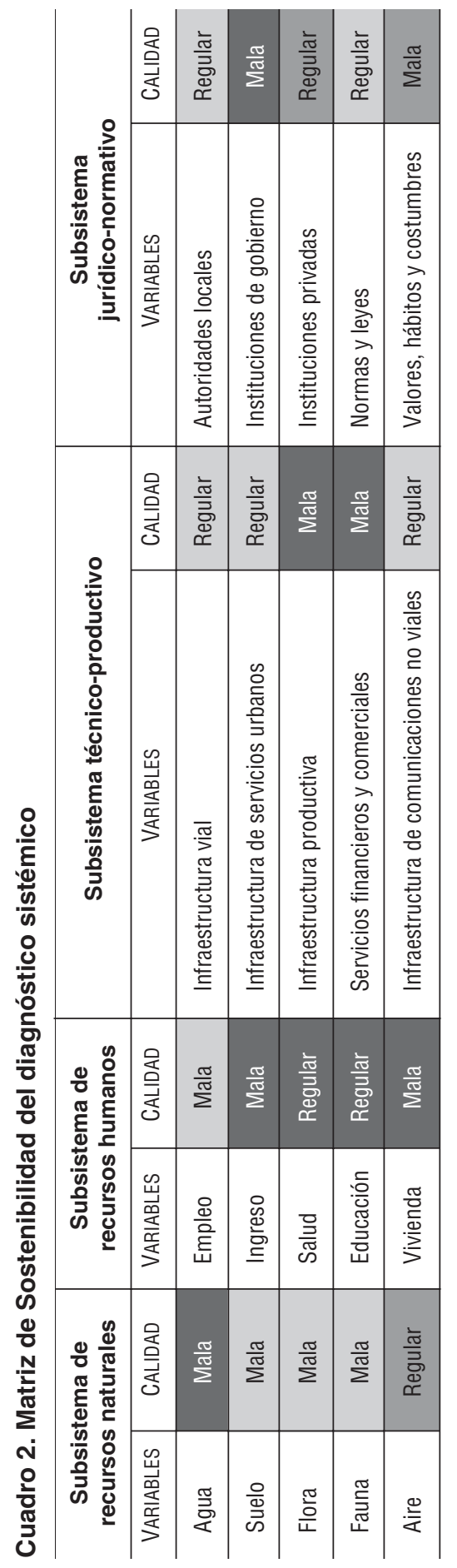




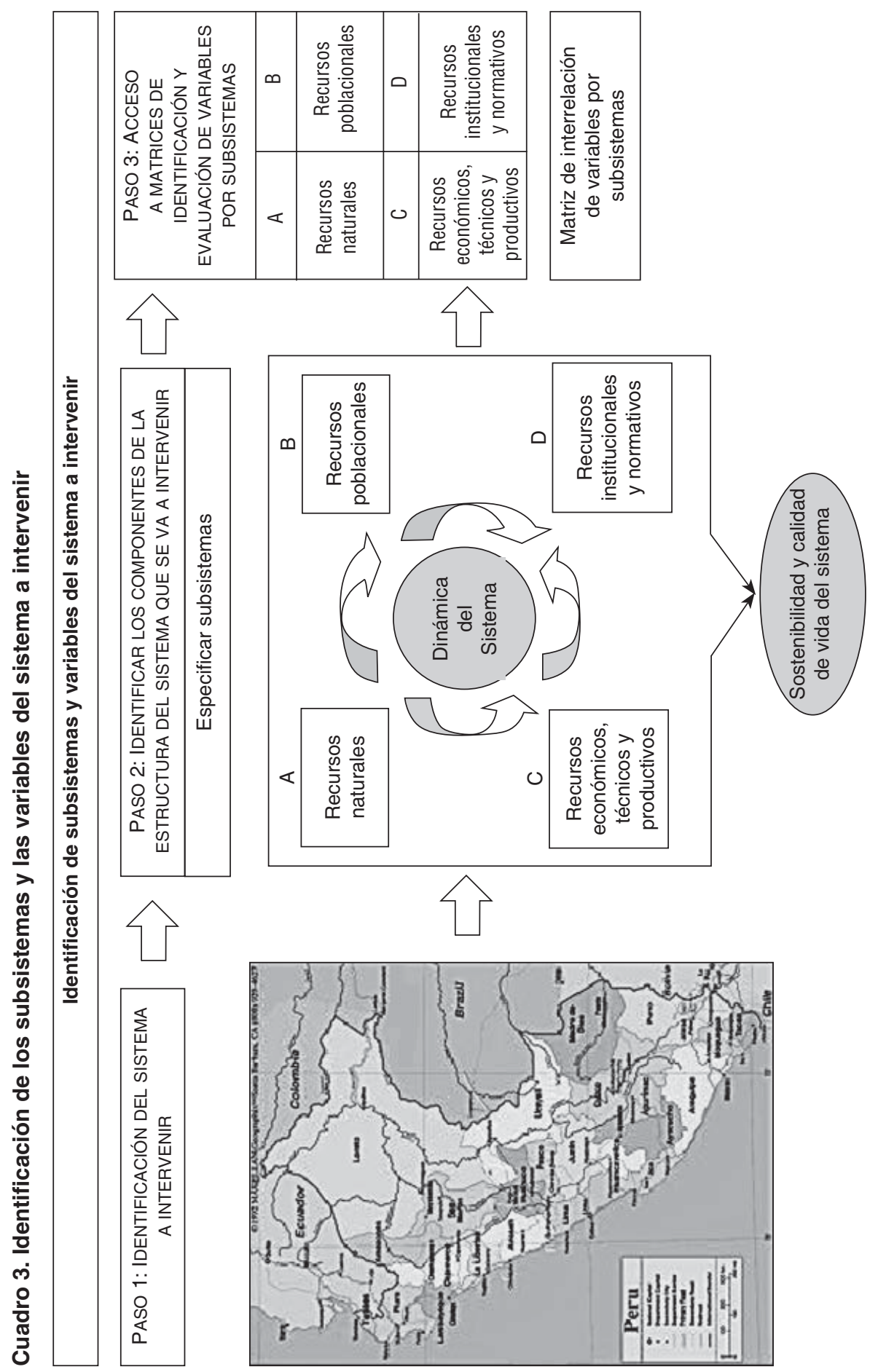




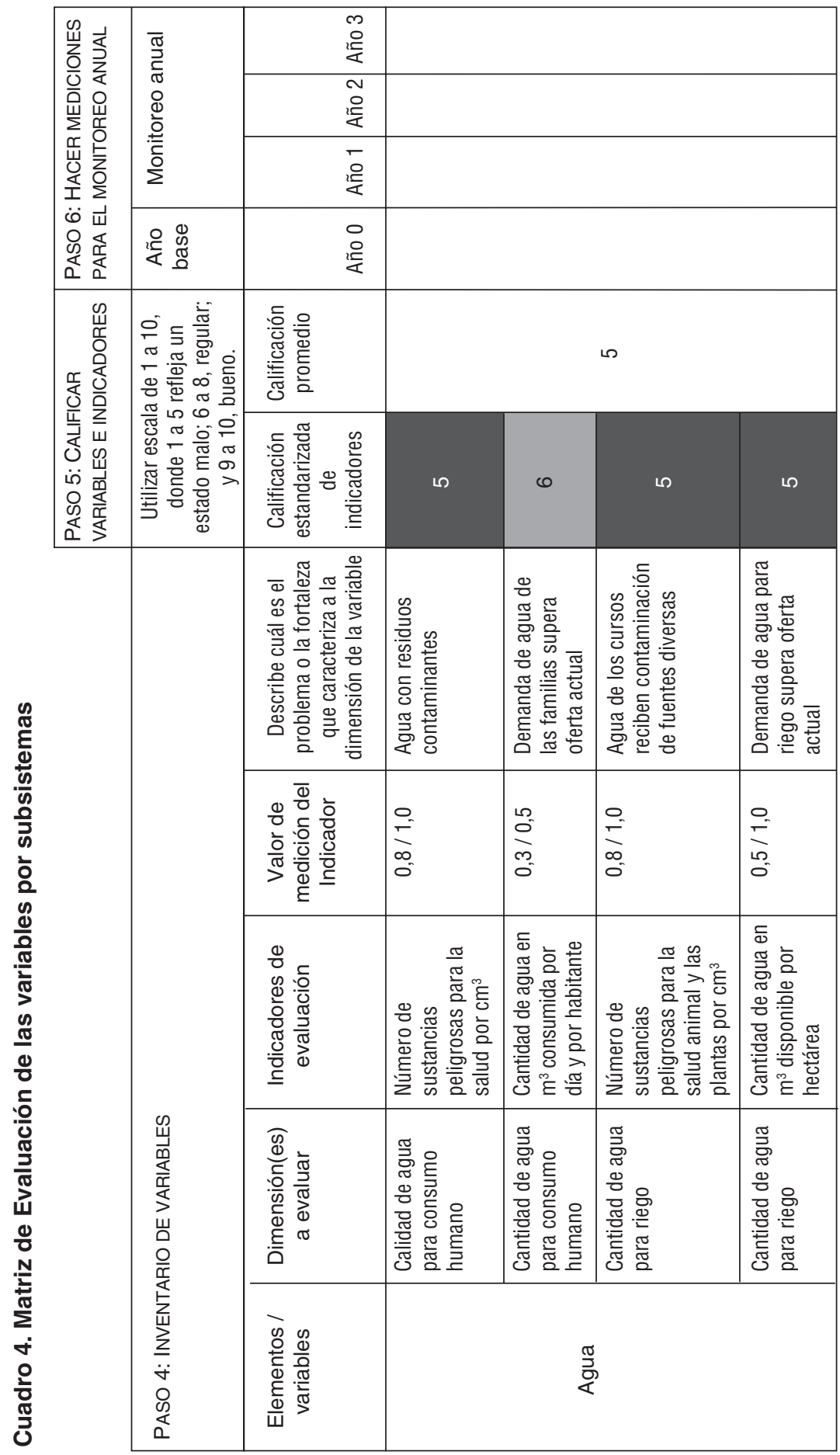


variable para facilitar su medición. Junto a las columnas de «elementos/variables» se especifican las dimensiones que pueden tener, así se identifica el aspecto que interesa medir y se evitan las generalidades. A continuación se consigue mayor precisión al solicitarse el indicador de evaluación, que es un paso previo a la obtención del valor de medición. El dato obtenido reflejará si la dimensión de la variable está en situación buena, regular o mala. Y eso debe traducirse en una breve descripción cualitativa, sea como problema o fortaleza. Finalmente, todas las dimensiones de cada variable se estandarizan en una escala de 1 a 10, donde 1 a 5 significa estado malo; 6 a 8, regular; y 9 a 10, bueno. El promedio simple de todas ellas será la calificación de la variable evaluada. El Project System arroja en forma automática el promedio.

Este proceso se sigue para todas las variables de todos los subsistemas. Conforme se obtienen las calificaciones, el modelo genera automáticamente la Matriz de Diagnóstico o de Sostenibilidad, sobre la cual se trabajará la siguiente etapa, es decir, la programación de las actividades y los proyectos de intervención para mejorar el estado de las variables que arrojaron un valor deficitario en el diagnóstico.

\section{Matriz de Diagnóstico, FODA y visión}

Como se ha señalado, la matriz que se genera como consecuencia de la evaluación de cada una de las variables de los diferentes subsistemas permite conocer el estado de cada subsistema y el del sistema global. Así, se pueden identificar las variables que son fuertes (trama clara), las que están en situación regular (trama intermedia) y las que están débiles (trama negra). La imagen de esta matriz es la que se ha presentado como Matriz de Sostenibilidad.

Además, a partir de esa matriz, el Project System construye de manera automática una matriz FODA (fortalezas, oportunidades, debilidades y amenazas) del sistema territorial como conjunto y, sobre esa base, se puede proponer una visión u objetivo de desarrollo de mediano o corto plazo (ver cuadro 5). Se puede observar como, de acuerdo con la calificación obtenida por cada variable, estas se alinean automáticamente, sea como fortalezas (trama clara) o debilidades (trama intermedia y negra).

El paso siguiente del análisis FODA consiste en identificar las fortalezas o las oportunidades que pueden afectar los diferentes subsistemas y luego ver cuáles afectan o favorecen el desarrollo de cada una (ver cuadro 6).

La Matriz de Debilidades y Amenazas es similar, solo que ordena las variables que se han evaluado como débiles y que, por tanto, pueden estar sujetas a una serie de amenazas (ver cuadro 7).

Una vez que el Project System ha asignado las diferentes variables en las matrices que les corresponden, es decir, de fortalezas o debilidades, muestra una serie de columnas donde los especialistas en desarrollo pueden listar las oportunidades o las amenazas, según sea el caso. Y, en función a ello, preparar las acciones necesarias para afrontar la situación que plantea cada una de ellas.

Si se trata de oportunidades que coinciden con la existencia de fortalezas, se buscará que se complementen para potenciar el desarrollo. Por ejemplo, si una fortaleza 
Cuadro 5. Matriz FODA

\begin{tabular}{|c|c|c|c|}
\hline \multirow[b]{2}{*}{ SUBSISTEMAS } & \multicolumn{3}{|c|}{ Matriz FODA } \\
\hline & VARIABLES & FORTALEZAS & DEBILIDADES \\
\hline \multirow[t]{4}{*}{ Recursos naturales } & Agua & & \\
\hline & Suelo & & 7 \\
\hline & Flora & 9 & \\
\hline & Fauna & & 7 \\
\hline \multirow[t]{4}{*}{ Recuros poblacionales } & Salud & & 6 \\
\hline & Educación & & 5 \\
\hline & Ingreso & & 6 \\
\hline & Vivienda & & 6 \\
\hline \multirow{4}{*}{$\begin{array}{l}\text { Recursos técnicos, } \\
\text { científicos y } \\
\text { productivos }\end{array}$} & Infraestructura vial & & 5 \\
\hline & $\begin{array}{l}\text { Infraestructura de } \\
\text { servicios urbanos }\end{array}$ & & 6 \\
\hline & $\begin{array}{l}\text { Infraestructura financiera y } \\
\text { comercial }\end{array}$ & & 5 \\
\hline & $\begin{array}{l}\text { Infraestructura de } \\
\text { comunicaciones no viales }\end{array}$ & 9 & \\
\hline \multirow{4}{*}{$\begin{array}{l}\text { Recursos institucionales, } \\
\text { jurídicos y } \\
\text { normativos }\end{array}$} & Gestión de autoridades & & 5 \\
\hline & $\begin{array}{l}\text { Eficiencia de } \\
\text { instituciones públicas }\end{array}$ & & 5 \\
\hline & $\begin{array}{l}\text { Cumplimiento de } \\
\text { normas y leyes }\end{array}$ & & 5 \\
\hline & $\begin{array}{l}\text { Respeto a valores, } \\
\text { buenos hábitos y } \\
\text { costumbres }\end{array}$ & 9 & \\
\hline
\end{tabular}

Variable muy débil
Variable débil
\begin{tabular}{|l}
$\square$ \\
$\square$ Variable fortaleza
\end{tabular}

de un espacio territorial es la existencia de playas con arenas limpias y un mar tranquilo, una oportunidad aprovechable puede ser la oferta de crédito o inversiones para potenciar actividades de turismo. Si se trata de amenazas que ponen en riesgo la integridad de una o más variables de alguno de los subsistemas, como puede ser la presencia de enfermedades epidémicas en lugares donde el agua no es potable o los residuos orgánicos no se recogen, se tratará de atender con urgencia esta situación y superar esas debilidades para evitar un daño que puede afectar gravemente la salud de la población.

\section{La etapa de planificación}

La Programación de Actividades y/o proyectos se hace con base en los resultados del diagnóstico sistémico; por tanto, se espera que las inversiones se realicen en primer lugar en aquellas variables o componentes del espacio territorial que arrojan valores críticos y que, de no atenderse, 


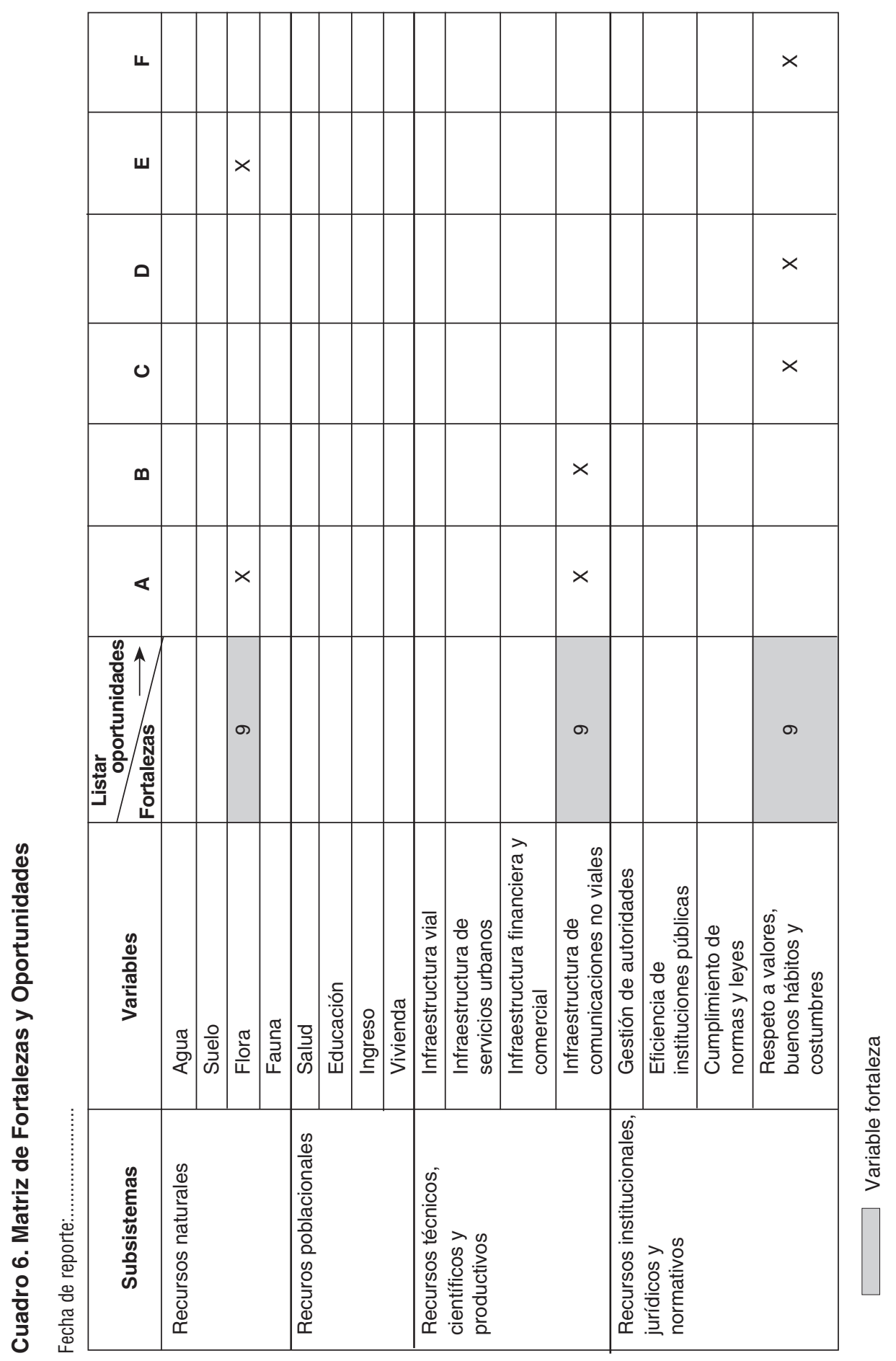




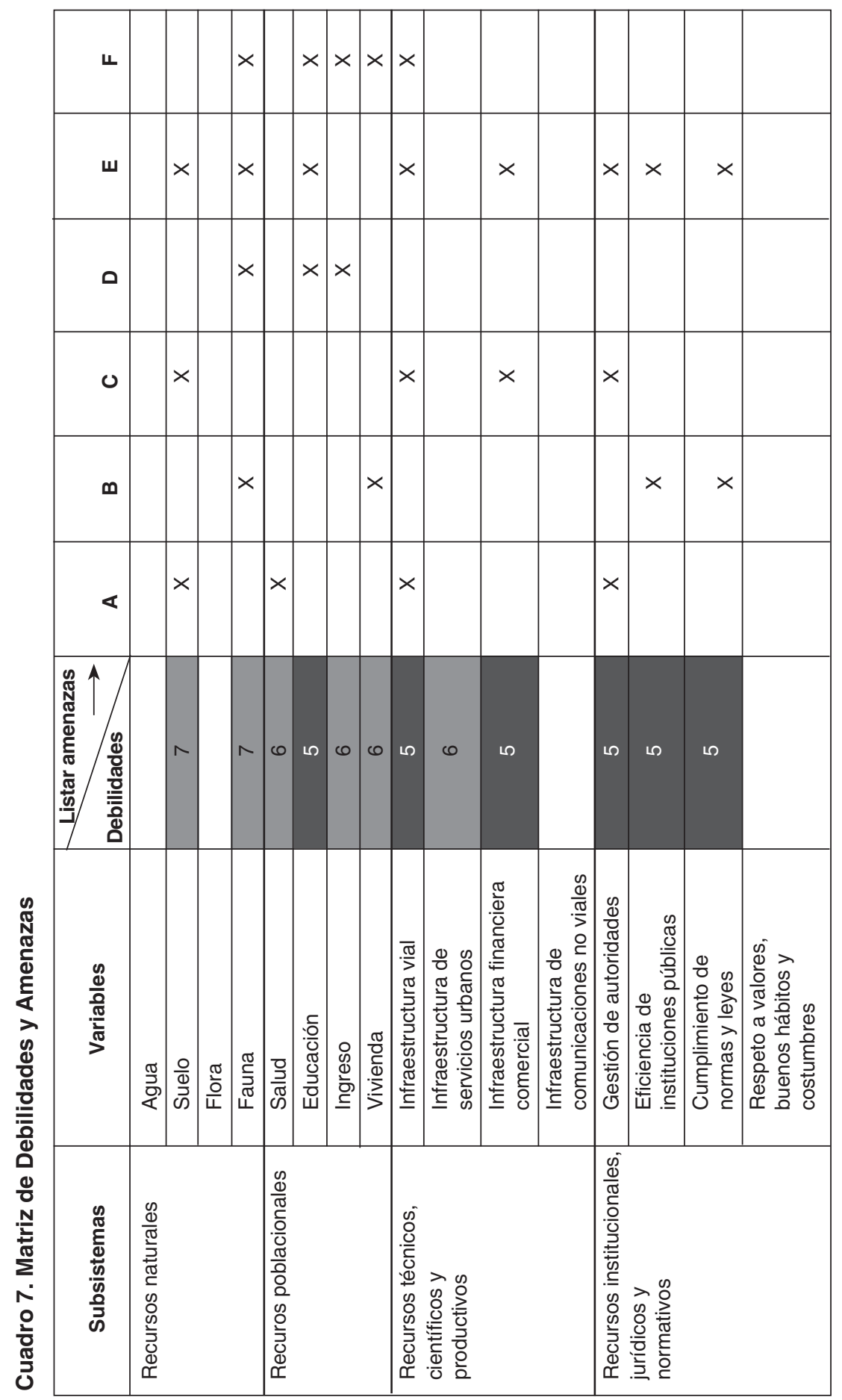


pueden empeorar la situación global. Ya se ha visto cómo la matriz FODA puede ayudar a la toma de decisiones para la programación inmediata o mediata de proyectos o actividades, sea para resolver problemas originados por las debilidades o para aprovechar las oportunidades sobre la base de una o más fortalezas.

El hecho de que una o más variables se encuentren en situación regular (trama intermedia) u óptima (trama clara) no significa que deje de intervenirse en ellas. En la práctica, las variables que están en situación regular necesitan pasar a la categoría de buenas para contribuir de manera positiva a la sostenibilidad del sistema y para ello debe actuarse sobre estas. Mientras que en el caso de las variables consideradas óptimas porque funcionan bien debe también considerarse la inversión para lograr que mantengan su nivel de eficiencia (operación y mantenimiento) y no caigan a niveles inferiores, de ser así, la actuación en la gestión del sistema sería irregular e inconsistente puesto que no se estaría actuando en función del equilibrio del conjunto, lo que es una práctica contraria a la sostenibilidad.

Es muy importante señalar que todo el proceso de diagnóstico y evaluación de los recursos y la planificación de los proyectos se hace con la población, de manera que esta siempre tendrá una participación activa y decisiva en la construcción y la gestión de la propuesta de desarrollo integral. En este sentido, desde el inicio de la tarea de aplicación de la metodología del Project System se debe dialogar con el gobierno local y las organizaciones vecinales para que elijan a los delegados que se capacitarán en las herramientas del sistema y puedan diagnosticar, planificar y monitorear con conocimiento y suficiencia técnica.
Cuando las herramientas de gestión estén construidas, se podrán colocar en la página de Internet de las instituciones aliadas para que toda persona que desee pueda informarse, opinar o participar del proceso de planificación y gestión.

\section{La Matriz de Planificación}

Una vez identificados los proyectos que se requieren para cumplir con los objetivos trazados y superar las deficiencias del sistema estudiado, se debe precisar tanto el área de actuación como el número de beneficiarios para cada proyecto. Se tendrá así una idea de a quiénes y dónde se producirán los resultados y los impactos esperados por el proyecto. Los resultados se refieren a los objetivos directos que busca el proyecto; mientras que los impactos se orientan a los beneficios indirectos que se generan como consecuencia de las actividades de estos. Por ejemplo, un proyecto cuya finalidad es la construcción de una fábrica tiene como resultado esperado que se produzca un tipo de bien o servicio que genere ingresos o satisfaga una necesidad, pero indirectamente generará demandas internas que promoverán otras actividades productivas y de servicios, de manera que no solo se beneficiarán los empleados directos de la fábrica sino también los de aquellas que ofrecerán bienes y servicios a dicha empresa y sus trabajadores.

En el Project System se planifican todos los proyectos necesarios para actuar en cada una de las variables, de manera que se tenga una intervención positiva sobre todo el sistema territorial y se eviten descuidos que luego puedan generar retrocesos en algunas de las variables y tener impactos negativos sobre el resto. Esto es lo que se quiere evitar con este método, pues de 


\begin{tabular}{|c|c|c|c|c|c|c|}
\hline \multirow{10}{*}{+2} & \multirow{2}{*}{ 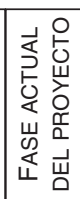 } & uọ!วnวə!ヨ & $\times$ & $\times$ & \multirow[b]{2}{*}{$\times$} & \multirow[b]{2}{*}{$\times$} \\
\hline & & 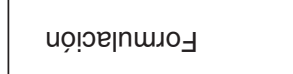 & & & & \\
\hline & \multirow{5}{*}{ 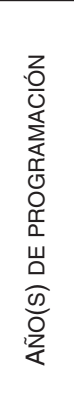 } & 호 & & & & \\
\hline & & 웅 & & & & $\times$ \\
\hline & & 。্े & & & $\times$ & $\times$ \\
\hline & & 。্ & $\times$ & $\times$ & $\times$ & \\
\hline & & ণิ & $\times$ & $\times$ & & \\
\hline & \multicolumn{2}{|l|}{ 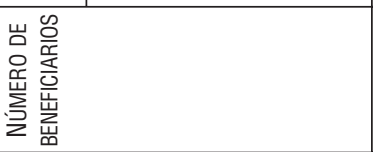 } & 迎 & 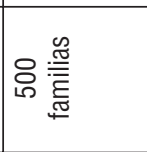 & 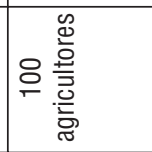 & 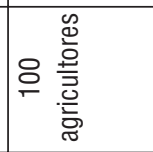 \\
\hline & \multicolumn{2}{|l|}{ 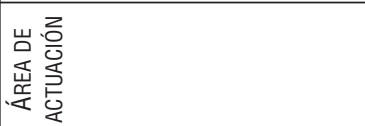 } & 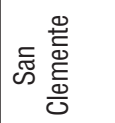 & 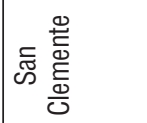 & 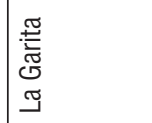 & 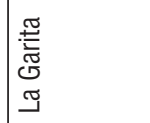 \\
\hline & 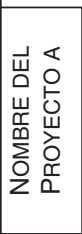 & 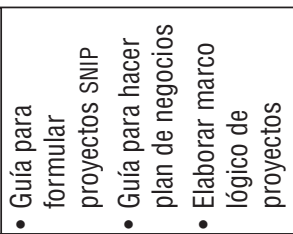 & 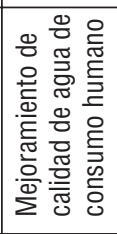 & 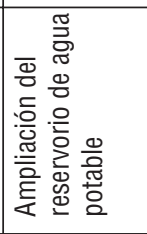 & 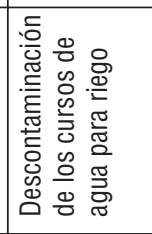 & 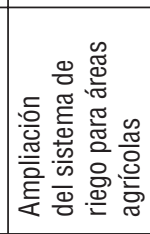 \\
\hline \multirow{4}{*}{$\begin{array}{l}\text { 을 } \\
\frac{0}{0} \\
.0 \\
\frac{0}{0} \\
\frac{\pi}{0}\end{array}$} & \multicolumn{2}{|c|}{ 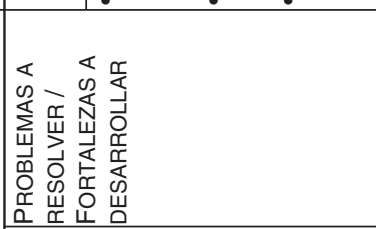 } & 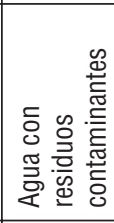 & 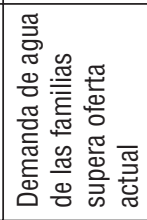 & 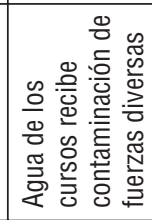 & 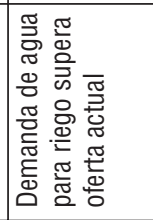 \\
\hline & \multicolumn{2}{|c|}{ 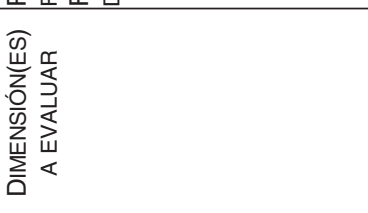 } & 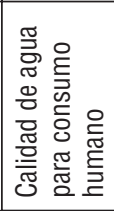 & 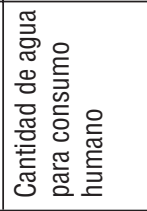 & 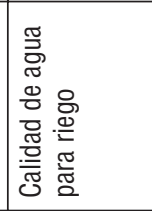 & 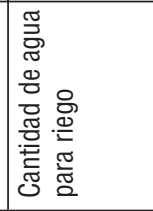 \\
\hline & \multicolumn{2}{|l|}{ 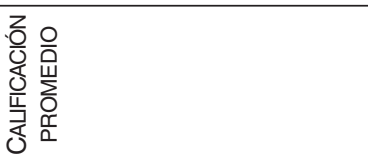 } & & \multicolumn{2}{|c|}{10} & \\
\hline & \multicolumn{2}{|c|}{ 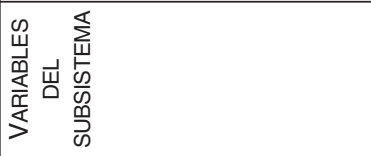 } & & \multicolumn{2}{|c|}{ 裉 } & \\
\hline
\end{tabular}


ocurrir esos descuidos no se cumpliría con el principio de planificar en función del desarrollo sostenible (ver cuadro 8).

Se debe señalar que el éxito de una intervención de estas características requiere contar con la participación de todos los actores sociales y de los agentes de desarrollo local, ya que son ellos quienes deberán continuar en el futuro y de manera permanente con esta práctica de diagnóstico, planificación e inversión. De lo contrario, el desarrollo se detiene, el sistema social se resiente y aparecen los conflictos y las crisis de tipo social.

En esta matriz se puede observar que el componente del diagnóstico está presente para ayudar de manera directa a la planificación. Así se evitará, por un lado, dejar de lado la priorización que debe darse a la solución de los problemas considerados urgentes. Y, por otra parte, se podrá evaluar si, dos o tres años más adelante de realizada la inversión para resolver alguno de los problemas identificados, la evaluación del diagnóstico ha cambiado con relación a dichas variables. De no ser así, esto significaría que el proyecto no identificó bien la(s) causa(s) del problema que lo generaba.

\section{Formulación y evaluación de proyectos}

El modelo de sostenibilidad económica y social del Project System incluye un menú para el aprendizaje y la formulación de proyectos mediante las herramientas de evaluación exigidas por el Sistema Nacional de Inversión Pública (SNIP); por ejemplo, el árbol de causas y efectos de los problemas, el costo beneficio, el costo efectividad y la matriz de impacto socioambiental, entre otros. Al igual que en los ins- trumentos anteriores, todo el proceso está automatizado. Los proyectos se organizan en sus respectivas matrices de subsistemas de acuerdo con su naturaleza y pueden ser gestionados y monitoreados en todos sus detalles desde el tablero de mando.

En el caso de proyectos que están sujetos a los procedimientos metodológicos del SNIP, desde la Matriz de Planificación se puede acceder a un submenú que contiene un guión con todos los pasos y las herramientas de gestión y análisis que este solicita. Siguiendo el procedimiento del cuadro 9 la elaboración de un proyecto de inversión es una tarea mucho más rápida y sencilla.

Asimismo, se incorpora un menú de acceso para formular proyectos que utiliza el marco lógico y las herramientas de gestión que deben acompañarlo, como son la matriz de consistencia, el diagrama de Gantt, el calendario físico, el calendario financiero y la matriz de seguimiento de resultados.

Este marco lógico es la herramienta principal para la formulación de un proyecto, pues allí se exponen los objetivos y los resultados a los que se pretende llegar, así como las actividades necesarias para lograrlos. Sin embargo, su formulación es solo un componente del desarrollo de un proyecto ya que la otra parte está dada por las herramientas de gestión. Por ejemplo, la matriz de consistencia ayuda a compatibilizar las actividades con los resultados esperados, y estos con el propósito y el fin del proyecto.

Pero, a su vez, el proyecto debe realizarse a lo largo de un tiempo determinado y, en este sentido, debe recurrir a un diagrama de Gantt para ordenar qué tareas son las que 


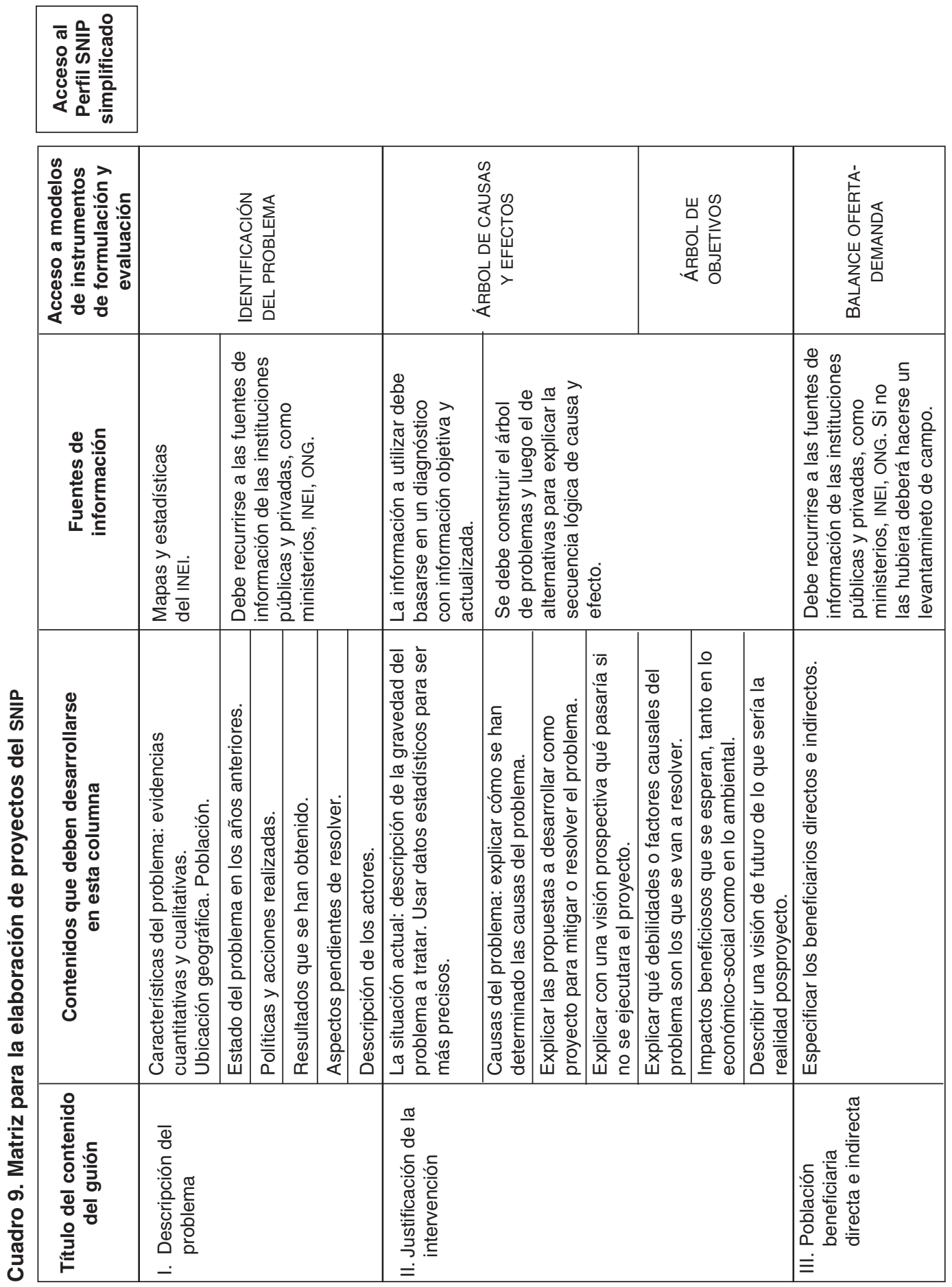


Cuadro 10. Marco lógico y herramientas de gestión

\begin{tabular}{|c|c|c|c|c|c|}
\hline \multicolumn{4}{|c|}{ Marco lógico } & \multirow{2}{*}{\multicolumn{2}{|c|}{$\begin{array}{c}\begin{array}{c}\text { Acceso a herramientas } \\
\text { complemento }\end{array} \\
\text { GESTIÓN DEL PROYECTO }\end{array}$}} \\
\hline $\begin{array}{l}\text { RESUMEN } \\
\text { NARRATIVO }\end{array}$ & $\begin{array}{l}\text { INDICADORES } \\
\text { VERIFICABLES }\end{array}$ & $\begin{array}{l}\text { MEDIOS DE } \\
\text { VERIFICACIÓN }\end{array}$ & SUPUESTOS & & \\
\hline $\begin{array}{l}\text { Fin al que contribuye } \\
\text { el proyecto }\end{array}$ & & & & $\begin{array}{l}\text { Matriz de } \\
\text { consistencia }\end{array}$ & $\begin{array}{l}\text { Diagrama de } \\
\text { Gantt }\end{array}$ \\
\hline $\begin{array}{l}\text { Propósito u } \\
\text { objetivo }\end{array}$ & & & & $\begin{array}{l}\text { Calendario } \\
\text { físico }\end{array}$ & $\begin{array}{l}\text { Calendario } \\
\text { financiero }\end{array}$ \\
\hline Productos & & & & $\begin{array}{l}\text { Matriz de } \\
\text { seguimiento } \\
\text { de resultados }\end{array}$ & \\
\hline Actividades & & & & Presupuesto & \\
\hline
\end{tabular}

anteceden a otras y tener una secuencia ordenada en el tiempo de manera que se determine aquellas tareas que están interrelacionadas y en las cuales una falla alteraría el tiempo de ejecución del proyecto. De otro lado, el calendario físico y el financiero ayudan a la programación de obras, tareas y gastos, lo que hace más fácil el seguimiento de la ejecución (ver cuadro 10).

Finalmente, cada proyecto debe tener un sistema de monitoreo para conocer cómo avanza el proceso de implementación de las actividades, y también debe tener tablas con indicadores que permitan medir los resultados, los objetivos o los propósitos esperados de su ejecución. Se debe tener en cuenta que el valor de la inversión no radica tanto en lo que se gasta en insumos y equipos, sino en los beneficios que la población va a obtener gracias a una nueva infraestructura, mejor capacitación o nuevos conocimientos que le permitirán mejorar sus condiciones de producción y de vida.

\section{EI Plan Operativo}

El Plan Estratégico se viabiliza mediante la formulación y la ejecución de los proyectos considerados necesarios para el desarrollo de la comunidad; por tanto, los proyectos pueden ser múltiples y diversos para un solo lugar. De no ejecutarse estos, el Plan Estratégico se convierte en un simple ejercicio de buenas intenciones sin ningún impacto real. En este sentido, cuando ya se ha establecido los proyectos considerados viables y estos cuentan con financiamiento, debe elaborarse un Plan Operativo para trabajar directamente con ellos. No todos los proyectos programados entran en este plan, puesto que muchos pueden no estar en fase de formulación o, a pesar de ser viables, no cuentan todavía con una asignación presupuestal.

El Project System parte de la información de la Matriz de Planificación y genera la siguiente matriz, en la cual solo se recogen los proyectos en fase de ejecución, de manera que se les puede hacer un seguimiento más directo y efectivo, separándolos de aquellos que están en etapa de formulación o programación para el futuro (ver cuadro 11).

En la matriz, en el rubro monitoreo, para cada proyecto se abrirá una ventana que permitirá el acceso al seguimiento 


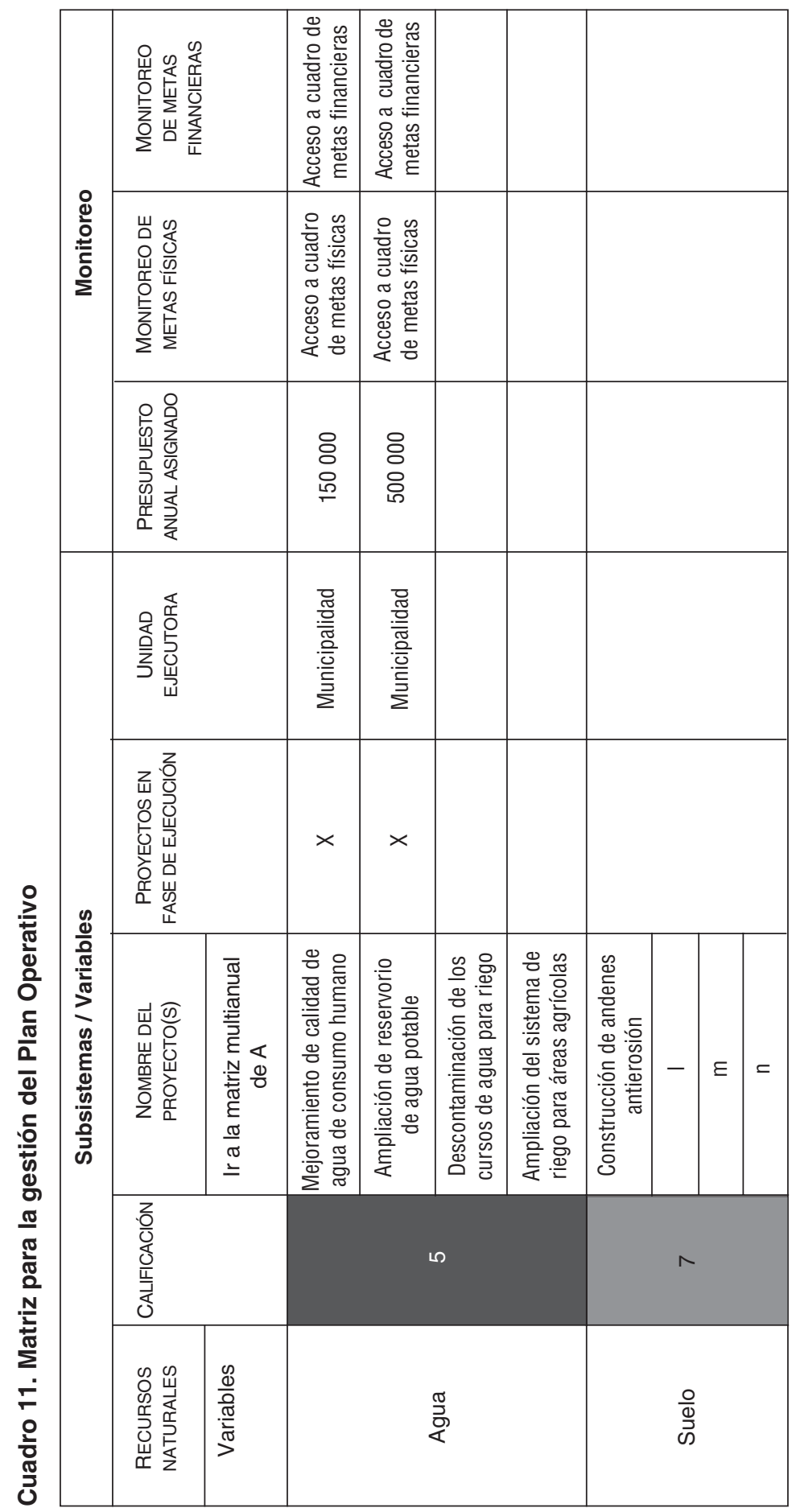


tanto de las metas físicas como de las metas financieras. Esto es muy importante para la adecuada gestión y la búsqueda del éxito para cada proyecto. En el fondo, el éxito de una intervención que busca el desarrollo sostenible depende de los logros de cada uno de sus proyectos específicos.

La gestión de cada proyecto debe hacerse con suficiencia técnica y debe contar con un sistema de monitoreo y evaluación. La buena y efectiva ejecución de los diferentes proyectos en un mismo espacio territorial crea sinergias que impactan de manera positiva en otros componentes del territorio.

\section{Proyecto empresarial}

Suele ocurrir también que muchas personas quieren elaborar proyectos para generar empresas de negocios. En este caso, lo que se necesita es una guía que ayude a realizar un plan con este fin. El Project System ha considerado esa posibilidad y, en el mismo submenú donde están el acceso a la guía del SNIP y el marco lógico, está también el acceso a una guía para crear un negocio empresarial.

Esta guía contiene un conjunto de pasos para que la persona interesada en generar un negocio para aprovechar la existencia en su entorno de una o más fortalezas con las que cuenta, y que busca transformar en oportunidades efectivas, sepa qué factores debe tener en cuenta para seleccionar el tipo de negocio que mejor se acomode a sus habilidades y se informe sobre todo el proceso productivo que requiere para la obtención de sus productos, así como acerca del mercado, la competencia y los precios.

Al final del artículo ver el anexo: Guía para elaborar un plan de negocios.

\section{EI Monitoreo estratégico de la Matriz de Sostenibilidad}

La vigencia del plan de desarrollo sostenible se sustenta en el monitoreo estratégico de la matriz de diagnóstico sistémico. Al realizarse el diagnóstico, el modelo genera también una Línea de Base y una Matriz de Monitoreo, cuyas variables serán medidas anualmente para saber si las inversiones que realizan los diversos proyectos impactan positivamente en la calidad de vida de las comunidades. De no ocurrir así, se deberán tomar de inmediato las medidas correctivas necesarias para impedir que se continúe cometiendo el error de hacer una inversión que no obtendrá los beneficios esperados.

Gracias a que el Project System incorpora una herramienta de monitoreo estratégico, se puede conocer cómo evolucionan las variables a medida que se hacen las inversiones de los distintos proyectos. Es de esperarse que, luego de cuatro o cinco años de inversiones importantes, como está ocurriendo en decenas de poblados del país gracias a los recursos provenientes sobre todo del canon minero y energético, en la imagen de las matrices de diagnóstico en las cuales resalta la trama negra, esta comience a cambiar por imágenes donde resalta la trama intermedia, y que donde destacaba hace algunos años esta, cuatro o cinco años después esas variables se vean reemplazadas en sus valores por la trama clara. En el ejemplo siguiente se ve cómo deberían producirse los cambios de las tramas según vaya mejorando el estado de las distintas variables (ver cuadro 12).

Para un adecuado monitoreo y evaluación del Plan de Inversiones es muy importante que se establezcan con claridad desde el inicio de la fase de diagnóstico los indicadores que darán cuenta del estado de 


\section{Cuadro 12. Matriz de Monitoreo Estratégico del modelo de sostenibilidad económico-social}

\begin{tabular}{|c|c|c|c|c|c|c|c|c|c|c|c|}
\hline \multicolumn{6}{|c|}{ Recursos naturales } & \multicolumn{6}{|c|}{ Recursos poblacionales } \\
\hline \multirow[t]{2}{*}{ VARIABLES } & \multirow{2}{*}{$\begin{array}{l}\text { CALIFICACIÓN } \\
\text { AÑO BASE } \\
\text { Añ̃o } 0\end{array}$} & \multicolumn{4}{|c|}{ MONITOREO POR AÑOS } & \multirow[t]{2}{*}{ VARIABLES } & \multirow{2}{*}{$\begin{array}{l}\text { CALIFICACIÓN } \\
\text { AÑO BASE } \\
\text { Añ̃o } 0\end{array}$} & \multicolumn{4}{|c|}{ MONITOREO POR AÑOS } \\
\hline & & Año 1 & Año 2 & Año 3 & Año 4 & & & Año 1 & Año 2 & Año 3 & Año 4 \\
\hline Agua & 5 & & & & & Salud & 5 & & & & \\
\hline Suelo & 7 & & & & & Educación & 4 & & & & \\
\hline Aire & 8 & & & & & Empleo & 3 & & & & \\
\hline Flora & 6 & & & & & Ingreso & 5 & & & & \\
\hline
\end{tabular}

\begin{tabular}{|c|c|c|c|c|c|c|c|c|c|c|c|}
\hline \multicolumn{6}{|c|}{ Recursos técnico-productivos } & \multicolumn{6}{|c|}{ Recursos institucionales y normativos } \\
\hline \multirow[t]{2}{*}{ VARIABLES } & \multirow{2}{*}{$\begin{array}{l}\text { CALIFICACIÓN } \\
\text { AÑO BASE } \\
\text { Añ̃ } 0\end{array}$} & \multicolumn{4}{|c|}{ MONITOREO POR AÑOS } & \multirow[t]{2}{*}{ VARIABLES } & \multirow{2}{*}{$\begin{array}{l}\text { CALIFICACIÓN } \\
\text { AÑO BASE } \\
\text { Año } 0\end{array}$} & \multicolumn{4}{|c|}{ MONITOREO POR AÑOS } \\
\hline & & Año 1 & Año 2 & Año 3 & Año 4 & & & Año 1 & Año 2 & Año 3 & Aก̃̃ 4 \\
\hline $\begin{array}{l}\text { Infraestructura } \\
\text { vial }\end{array}$ & 5 & & & & & $\begin{array}{l}\text { Gestión de } \\
\text { autoridades }\end{array}$ & 5 & & & & \\
\hline $\begin{array}{l}\text { Infraestructura } \\
\text { de servicios } \\
\text { urbanos }\end{array}$ & 7 & & & & & $\begin{array}{l}\text { Eficiencia de } \\
\text { instituciones } \\
\text { públicas }\end{array}$ & 4 & & & & \\
\hline $\begin{array}{l}\text { Infraestructura } \\
\text { productiva }\end{array}$ & 8 & & & & & $\begin{array}{l}\text { Eficiencia de } \\
\text { instituciones } \\
\text { privadas }\end{array}$ & 3 & & & & \\
\hline $\begin{array}{l}\text { Infraestructura } \\
\text { financiera y } \\
\text { comercial }\end{array}$ & 6 & & & & & $\begin{array}{l}\text { Cumplimiento } \\
\text { de normas } \\
\text { y leyes }\end{array}$ & 5 & & & & \\
\hline
\end{tabular}

cada variable según las dimensiones que les correspondan, y que esta medición se repita anualmente, en la medida que continúe el plan. Se debe precisar que si nuevos diagnósticos contienen nuevas variables, estas se deben incorporar para ser monitoreadas y evaluadas igual que el resto.

\section{El ciclo de retroalimentación del modelo}

La secuencia del modelo tiene una lógica de retroalimentación que permite que los logros puedan ir de menos a más. Así, partiendo del diagnóstico sistémico, recién se pueden proponer la visión y los objetivos estratégicos, en seguida se hace la propuesta de los programas de desarrollo con sus respectivos proyectos y se miden los resultados.

Se debe esperar que los proyectos generen impactos que beneficien a los pobladores de las comunidades. La magnitud de estos impactos son evaluados y los proyectos, a su vez, mejorados. Si esto ocurre, la acumulación de los impactos positivos se reflejará como cambios que afianzan la sostenibilidad del territorio, puesto que la interrelación positiva de los proyectos y sus resultados redundará en mejores condiciones de vida. De continuar esta tendencia, se podrán ver cambios significativos en el mediano plazo. 


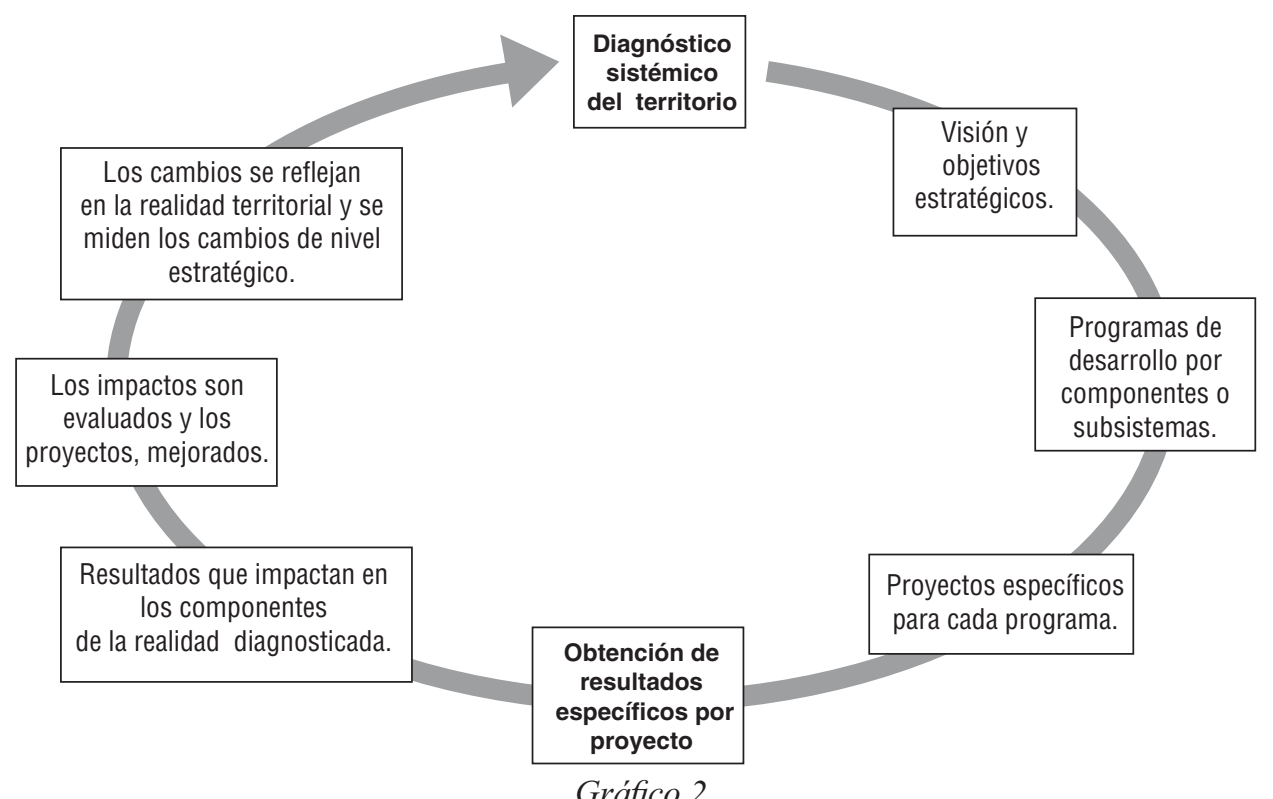

Ciclo de retroalimentación del modelo

\section{Conclusión}

\section{El Project System, una metodología que orienta el trabajo y facilita la consecución de los objetivos del desarrollo sostenible}

El Project System, si bien es un conjunto de herramientas articuladas, se sustenta en una metodología que señala los pasos a seguir para trabajar los espacios territoriales en función del desarrollo sostenible. Seguir la secuencia de las etapas explicitadas conduce fácilmente a la construcción de todos los instrumentos que hacen posible gestionar con éxito un Plan de Inversiones en proyectos que mejoren con una perspectiva clara y segura las condiciones de vida de cualquier población.

Una ventaja adicional y muy importante es que todos los componentes del sistema están integrados en un software que facilita la labor de los planificadores y los administradores de los proyectos ya que, conforme se generan las bases de datos de las diferentes herramientas del sistema, automáticamente se interrelacionan y alimentan entre ellas produciendo la información necesaria para la toma de decisiones en tiempo real e instantáneo. Esto significa que se pueden modelar los escenarios con diferentes posibilidades de futuro y grabar esas imágenes en función de distintas hipótesis que pueden darse en la realidad. Con ello se ayuda a la previsión y el diseño de planes alternativos o de contingencia para poder siempre acercarse al cumplimiento de los objetivos, a pesar de los imprevistos que puedan darse por diversas circunstancias.

Podemos decir que la consecución del desarrollo sostenible y la paz social necesaria para continuar con las inversiones y la mejora de las condiciones de vida de las poblaciones son objetivos que tienen un buen aliado técnico en la metodología del Project System. 


\section{ANEXO: GUÍA PARA ELABORAR UN PLAN DE NEGOCIOS EN FUNCIÓN DEL DESARROLLO SOSTENIBLE}

\section{Paso I: Analice sus preferencias y fortalezas}

- ¿Qué sabe hacer?

Exponga lo que mejor sabe hacer en orden de destreza de mayor a menor.

1)

2)

3)

- ¿Qué le entusiasma hacer?

De las cosas que sabe hacer, exponga lo que más le entusiasmaría hacer como para iniciar una actividad empresarial.

- Exponga los aspectos que considera que son sus principales fortalezas para aplicarlas y desarrollarlas en la actividad empresarial que le gustaría desarrollar.

1)

2)

3)

- ¿Cuánto tiempo y esfuerzo puede dedicar desde ahora para mejorar aquello que más le gustaría hacer?

\begin{tabular}{|l|l|l|}
\hline Horas al día & Días a la semana & Semanas al mes \\
\hline & & \\
\hline
\end{tabular}

\section{Paso II: Piense con sentido empresarial}

- Considere qué bien(es) o servicio(s) puede generar a partir de aquello que le gusta o sabe hacer.

\begin{tabular}{|l|l|}
\hline Bienes & Servicios \\
\hline & \\
& \\
\hline & \\
\hline
\end{tabular}


- Decida qué tipo de producto o servicio quiere ofrecer.

De la lista que ha escrito, seleccione uno o dos en los que debe concentrarse al inicio.

\begin{tabular}{|l|l|}
\hline Bienes & Servicios \\
\hline & \\
\hline
\end{tabular}

- ¿Cómo y dónde puede mejorar sus habilidades en aquello que le gusta o sabe hacer?

\begin{tabular}{|l|l|}
\hline Cómo mejorar & Dónde mejorar \\
\hline & \\
\hline
\end{tabular}

- ¿Quién o quiénes podrían ayudarlo para mejorar sus habilidades en lo que quiere hacer? Haga una relación con nombres y diga por qué los incluye.

\begin{tabular}{|l|l|l|l|l|}
\hline Amigo(s) & Pariente(s) & Jefe(s) & Profesor(es) & Otro(s) \\
\hline & & & & \\
& & & & \\
& & & & \\
\hline
\end{tabular}

- ¿Tiene recursos económicos para iniciar un negocio?

\begin{tabular}{|l|l|}
\hline Sí & No \\
\hline Cifra aproximada: & \\
\hline
\end{tabular}

- De primera impresión ¿cuánto calcula que necesita para iniciar su negocio? Tenga en cuenta que se requiere calcular gastos de local, servicios básicos como agua y energía eléctrica, insumos, licencias, pago de salarios, transporte, gastos notariales y publicidad, si fuera el caso.

\begin{tabular}{|l|l}
\hline En nuevos soles: & En dólares:
\end{tabular}

- ¿Hay familiares, amigos, ONG o entidades financieras que podrían interesarse y apoyarlo económicamente en su idea de negocio? Haga una lista de cada uno de ellos si es el caso.

\begin{tabular}{|l|l|l|l|l|}
\hline Familiares & Amigos & ONG & Bancos & Otros \\
\hline & & & & \\
\hline
\end{tabular}


- ¿Existen facilidades locales para invertir en ciertos tipos de negocio y que podrían ser una ventaja competitiva para lo que usted está pensando?

Por ejemplo, exoneraciones de ciertos tipos de tributos, créditos especiales con intereses más bajos para ciertos bienes o productos, beneficios arancelarios para importación de insumos, maquinarias, parque industrial subsidiado, etc. O beneficios para la exportación de ciertos bienes y productos.

Haga una relación de aquellos aspectos en los que puede encontrar beneficios especiales.

Tipos de beneficios y su descripción

\begin{tabular}{|l|l|l|l|l|}
\hline 1. & 2. & 3. & 4. & 5. \\
\hline & & & & \\
& & & & \\
\hline
\end{tabular}

\section{Paso III: Analice el mercado}

- ¿Existe en su localidad o fuera de ella alguna demanda potencial o no satisfecha relacionada con aquello que usted quiere hacer?

Indique en qué lugares existe esa demanda potencial, precisando ubicación geográfica. Fundamente el por qué existe una demanda que justifique la inversión en la cual está pensando.

\begin{tabular}{|l|l|l|l|}
\hline Nivel local & Nivel regional & Nivel nacional & Nivel internacional \\
\hline & & & \\
& & & \\
\hline
\end{tabular}

- Averigüe si en su localidad hay experiencias de negocios que ya están atendiendo o han atendido esa demanda de bienes o servicios en la que quiere incursionar.

Indique los nombres de esos negocios y averigüe en qué situación económica se encuentran.

\begin{tabular}{|l|l|l|l|l|}
\hline 1. & 2. & 3. & 4. & 5. \\
\hline & & & & \\
& & & & \\
\hline
\end{tabular}


- ¿Cuáles son las fortalezas y las debilidades de esos negocios?

Fortalezas

\begin{tabular}{|l|l|l|l|l|l|}
\hline 1. & 2. & 3. & 4. & 5. & 6. \\
\hline & & & & & \\
\hline
\end{tabular}

Debilidades

\begin{tabular}{|l|l|l|l|l|l|}
\hline 1. & 2. & 3. & 4. & 5. & 6. \\
\hline & & & & & \\
\hline
\end{tabular}

- ¿Qué lecciones puede sacar de esas fortalezas y debilidades?

- Averigüe los precios de mercado del bien o servicio que quiere ofrecer, así como de los productos sustitutos, es decir, que pueden satisfacer la misma necesidad aunque no sean iguales.

\begin{tabular}{|l|l|l|l|l|l|}
\hline $\begin{array}{l}\text { Precio del } \\
\text { producto 1 }\end{array}$ & $\begin{array}{l}\text { Precio del } \\
\text { producto 2 }\end{array}$ & $\begin{array}{l}\text { Precio del } \\
\text { producto 3 }\end{array}$ & $\begin{array}{l}\text { Precio del } \\
\text { producto 4 }\end{array}$ & $\begin{array}{l}\text { Precio del } \\
\text { producto 5 }\end{array}$ & $\begin{array}{l}\text { Precio del } \\
\text { producto 6 }\end{array}$ \\
\hline & & & & & \\
\hline
\end{tabular}

\section{Paso IV: Averigüe sobre el proceso de producción del bien}

- ¿Hay proveedores locales de los insumos que necesita o debe traerlos de fuera?

Haga una lista de los insumos que requerirá y de los proveedores, dependiendo de su origen.

\begin{tabular}{|l|l|l|l|l|}
\hline Insumos & $\begin{array}{l}\text { Proveedores } \\
\text { locales }\end{array}$ & $\begin{array}{l}\text { Proveedores } \\
\text { regionales }\end{array}$ & $\begin{array}{l}\text { Proveedores } \\
\text { nacionales }\end{array}$ & $\begin{array}{l}\text { Proveedores } \\
\text { internacionales }\end{array}$ \\
\hline & & & & \\
\hline & & & & \\
\hline & & & & \\
\hline & & & & \\
\hline
\end{tabular}


- ¿Los insumos son de la calidad y la cantidad que piensa requerir? Averigüe qué proveedores le ofrecen las mejores condiciones en calidad y cantidad.

\begin{tabular}{|l|l|}
\hline En cantidad & En calidad \\
\hline & \\
\hline & \\
\hline & \\
\hline & \\
\hline
\end{tabular}

- Haga un gráfico donde se ubiquen todos los pasos del proceso para la realización del bien o producto que quiere ofrecer.

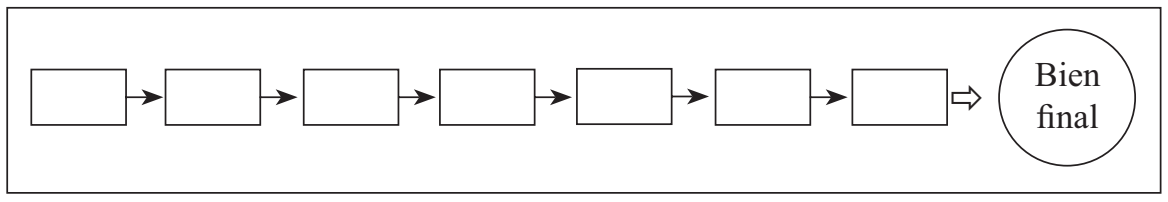

- Asegúrese, marcando con un visto bueno, si está en condiciones de poder cubrir todas las fases de producción, venta y entrega del bien.

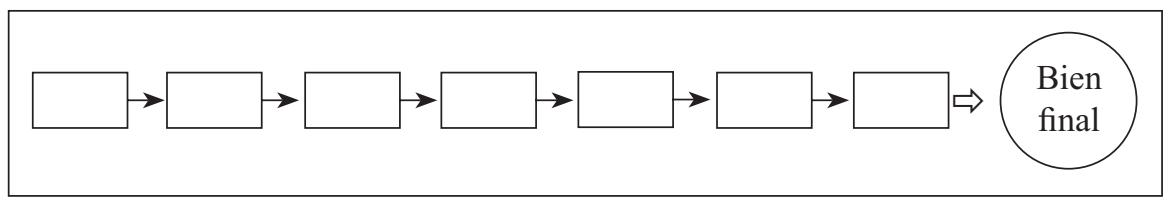

Si hay partes del proceso que no puede cumplir, especifique quién podría satisfacer esa parte de la producción.

\begin{tabular}{|l|l|}
\hline Partes del proceso que requerirán servicio & Entidad que dará el servicio \\
\hline & \\
\hline & \\
\hline & \\
\hline & \\
\hline
\end{tabular}




\section{Paso V: Considere el personal que lo acompañará en su proyecto}

- ¿Existe en su localidad la oferta de mano de obra necesaria para su proyecto?

\begin{tabular}{|l|l|}
\hline Sí & No \\
\hline $\begin{array}{l}\text { ¿Dónde } \\
\text { la ubica? }\end{array}$ & $\begin{array}{l}\text { ¿Dónde tendría } \\
\text { que buscarla? }\end{array}$ \\
\hline
\end{tabular}

- ¿Requerirá darle una capacitación previa antes de empezar el trabajo?

\begin{tabular}{|l|l|}
\hline Sí & No \\
\hline ¿Cómo dará la capacitación? & \\
\hline ¿Quién dará la capacitación? & \\
\hline
\end{tabular}

- ¿Preferiría trabajar con familiares, amigos o terceras personas? Evalúe lo más conveniente en función a los criterios de capacidad y confianza.

Dé razones para cada caso.

\begin{tabular}{|l|l|l|}
\hline Con familiares & Con amigos & Con terceras personas \\
\hline & & \\
& & \\
& & \\
\hline
\end{tabular}

- Entérese de la legislación en materia de contratación laboral.

Haga un resumen de los aspectos más relevantes y tenga en cuenta que deberá cumplir con ellos. 


\section{Paso VI: Haga un análisis de rentabilidad}

- ¿A cuánto ascenderá su costo por unidad teniendo en cuenta el volumen de producción inicial proyectado, incluyendo pago por insumos, salarios, alquiler de local, servicios, licencias, beneficios sociales, etc.? Y también el pago de intereses si obtuviera un préstamo.

Total del volumen inicial de unidades de producción por periodo mensual

Especificar costos por unidad

\begin{tabular}{|l|l|l|l|l|l|l|l|}
\hline $\begin{array}{l}\text { Insumos } \\
\text { yastos } \\
\text { diversos }\end{array}$ & & & & & & & $\begin{array}{l}\text { Total del } \\
\text { costo por } \\
\text { unidad }\end{array}$ \\
\hline $\begin{array}{l}\text { Costo en } \\
\text { soles }\end{array}$ & & & & & & & \\
\hline
\end{tabular}

- Calcule hasta cuánto puede bajar el costo por unidad si dobla la producción inicial.

Volumen de producción duplicado por periodo mensual

Especificar costos por unidad

\begin{tabular}{|l|l|l|l|l|l|l|l|}
\hline $\begin{array}{l}\text { Insumos } \\
\text { yastos } \\
\text { diversos }\end{array}$ & & & & & & & $\begin{array}{l}\text { Total del } \\
\text { costo por } \\
\text { unidad }\end{array}$ \\
\hline $\begin{array}{l}\text { Costo en } \\
\text { soles }\end{array}$ & & & & & & & \\
\hline
\end{tabular}

- Calcule el precio de venta por unidad, en función al volumen inicial de producción, que le permitirá obtener un beneficio o utilidad de acuerdo con sus expectativas.

\begin{tabular}{|l|l|l|}
\hline Costo por unidad & Más ganancia & Menos precio de venta \\
\hline $\mathrm{S} /$. & $\mathrm{S} /$. & $\mathrm{S} /$. \\
\hline
\end{tabular}

- Calcule el costo de su producción mensual en función del volumen de producción estimado:

Costo mensual $=$ Volumen de producción mensual por costo unitario 
- Calcule los ingresos mensuales a obtener con base en el volumen de ventas proyectado y el precio de venta que ha pensado para su producto:

Ingreso $=$ Volumen de ventas por precio de venta por unidad

- Calcule cuánto necesita vender al mes para cubrir todos los costos de producción:

Volumen de venta mínimo $=$ Costo mensual de producción $/$ precio de venta por unidad

\begin{tabular}{|l|l|l|}
\hline $\begin{array}{l}\text { A. Venta mínima } \\
\text { en unidades } \\
\text { para cubrir costos }\end{array}$ & $\begin{array}{l}\text { B. Venta óptima } \\
\text { en unidades según } \\
\text { expectativas }\end{array}$ & $\begin{array}{l}\text { Ganancia proyectada } \\
(\mathrm{B}-\mathrm{A})\end{array}$ \\
\hline & & \\
\hline
\end{tabular}

- Compare el precio de venta calculado para su producto con los precios actuales de los productos de la competencia:

\begin{tabular}{|l|l|}
\hline $\begin{array}{l}\text { Precio de venta para } \\
\text { productos propios }\end{array}$ & $\begin{array}{l}\text { Precio promedio de venta de los } \\
\text { productos equivalentes de la } \\
\text { competencia }\end{array}$ \\
\hline S/. & S/. \\
\hline
\end{tabular}

- Deduzca si su precio será competitivo en función a la que será la calidad de su producto.

- Calcule el monto total de su inversión tomando en cuenta todos los elementos de insumos, infraestructura, personal, gastos legales, etc. que requerirá para el volumen de producción con el que espera iniciar su negocio.

Especifique cuánto del monto podrá obtenerlo de sus ahorros y cuánto deberá ser financiado por otra entidad mediante un préstamo o sociedad.

\begin{tabular}{|l|l|l|}
\hline Monto total de la inversión & Capital propio & Capital a financiar \\
\hline S/. & S/. & S/. \\
\hline
\end{tabular}

Tener en cuenta que, en caso de necesitar un préstamo en dinero, el capital a financiar estará sujeto a un interés que debe cargarse al precio del producto. Es conveniente asesorarse con un especialista para saber en cuánto se incrementa el costo del producto por el interés financiero. 


\section{Paso VII: Responsabilidad social. Efectúe un análisis del impacto ambiental y social de su producción}

- ¿Su actividad económica va a utilizar insumos que contaminan el medio ambiente?

Consulte con especialistas para tener respuestas certeras.

\begin{tabular}{|l|l|}
\hline Sí & No \\
\hline Especificar cuáles: & \\
& \\
\hline
\end{tabular}

- De ser el caso ¿qué medidas va a tomar para evitar esa contaminación?

Describa cómo va a evitar la contaminación. Tener en cuenta que el costo de evitar la contaminación a posteriori generalmente repercute en el costo del producto o en el margen de ganancias. Por eso es mejor iniciar el plan de producción considerando insumos y tecnologías no contaminantes.

- Su actividad ¿va a extraer recursos naturales?

\begin{tabular}{|l|l|}
\hline Sí & No \\
\hline Especifique: & \\
& \\
\hline
\end{tabular}

- Si son recursos renovables ¿cómo piensa renovar los recursos?

Detalle el proceso de renovación. Asesórese con un especialista. 
- Si no son renovables ¿cómo va a compensar al medio natural y a la sociedad por el deterioro ocasionado por la extracción de los recursos?

\begin{tabular}{|l|l|}
\hline Compensación a la sociedad & Compensación al medio natural \\
\hline & \\
\hline
\end{tabular}

- Si hay actividades de riesgo en el trabajo ¿qué medidas de seguridad laboral y de higiene industrial se adoptarán para proteger a los trabajadores?

\begin{tabular}{|l|l|}
\hline Actividades riesgosas & Medidas de seguridad para evitarlas \\
\hline & \\
& \\
\hline
\end{tabular}

- Desarrolle un código de ética y conducta para los funcionarios y los trabajadores de su empresa, de manera que se logre un impacto positivo hacia dentro y hacia el entorno social.

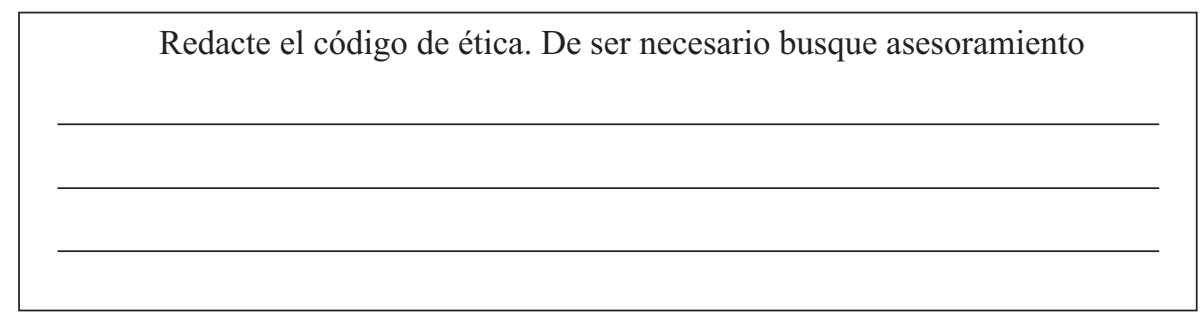

Revise la legislación relacionada con la gestión ambiental y haga una síntesis de ella, en particular en los aspectos relacionados con la actividad que piensa realizar. Es recomendable asesorarse con un especialista.

Haga un resumen de la legislación en lo que concierne a la actividad planificada 
- Considere un programa de relaciones de colaboración con la población que está en el entorno de la empresa. La empresa es una institución social que se debe a sus clientes, a los trabajadores y sus familiares.

Enumere las partes principales del programa y describa el papel de la empresa y el de la población

\begin{tabular}{|l|l|}
\hline $\begin{array}{l}\text { Programa y compromiso } \\
\text { con la empresa }\end{array}$ & $\begin{array}{l}\text { Papel y compromiso con la población } \\
\text { con la población }\end{array}$ \\
\hline & \\
\hline
\end{tabular}

Paso VIII: Repase todo lo que ha completado y tome la decisión más adecuada. Si no le satisfacen los resultados, inténtelo con otro tipo de bienes o productos. 